\title{
Luxação Metacarpofalângica do Polegar na Criança
}

\section{Dislocation of the Metacarpophalangeal Joint of the Thumb in a Child}

\author{
Carlos Durão ${ }^{1}$
}

Autor Correspondente:

\section{RESUMO}

Luxações isoladas das articulações metacarpofalângicas nas crianças são muito raras, sendo escassos os relatos na literatura. Isto pela fragilidade das físes, que pelo traumatismo associado, normalmente se separam em vez da ocorrência da luxação da articulação adjacente. Este trabalho apresenta o relato de um caso, discutindo a importância da atempada redução e as eventuais complicações descritas nestas lesões.

PALAVRAS-CHAVE: Articulação Metacarpofalângica/lesões; Criança; Luxações; Polegar/lesões

\section{ABSTRACT}

The metacarpophalangeal joint dislocation of the thumb in children is very rare, primarily because of the weakness of the physes, which separate instead of the adjacent joint's becoming dislocated. This paper presents a case report, discussing the importance of prompt reduction and possible complications described in these lesions.

KEY WORDS: Child; Dislocations; Metacarpophalangeal Joint/injuries; Thumb/injuries

\section{INTRODUÇÃO}

Luxações isoladas das articulações metacarpofalângicas nas crianças são muito raras, sendo escassos os relatos na literatura. ${ }^{1}$ Isto pela fragilidade das físes, que pelo traumatismo associado, normalmente se separam em vez da ocorrência da luxação da articulação adjacente..$^{2-4}$ Este trabalho apresenta o relato de um caso, discutindo a importância da atempada redução e as eventuais complicações descritas nestas lesões.

\section{RELATO DE CASO}

Relato de caso de uma criança de 9 anos, sexo masculino, com traumatismo e entorse do polegar direito após queda de bicicleta. Deu entrada no Serviço de Urgência com tumefação traumática e muitas queixas álgicas localizadas no polegar direito, com impotência funcional deste.

Foi realizada radiografia da mão em AP e perfil que evidenciou uma luxação isolada da articulação metacarpofalângica do $1^{\circ}$ dedo da mão direita. Foi realizada 

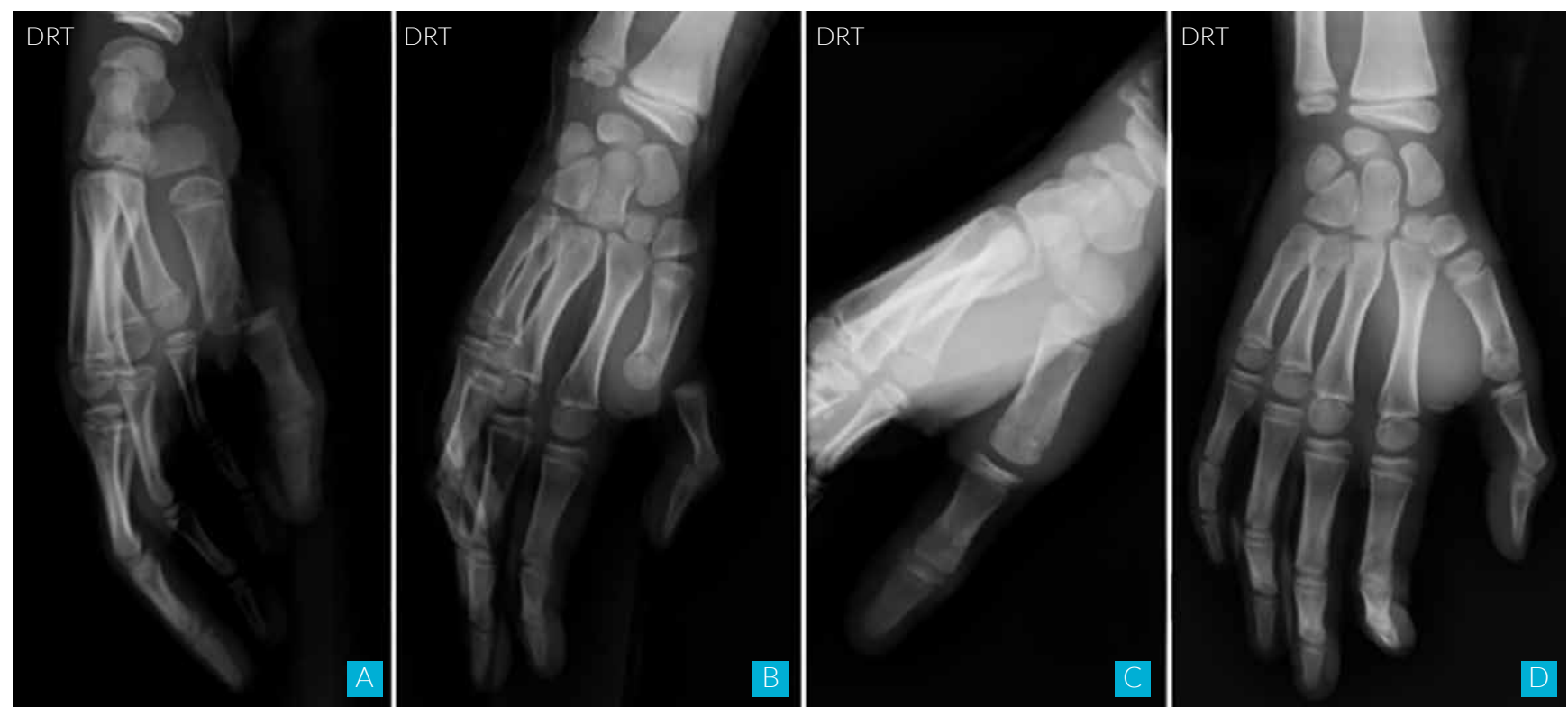

FIGURA 1. Radiografia da luxação metacapofalângica do $1^{\circ}$ dedo (A-B). Radiografia de controle, mostrando a correta redução (C-D).

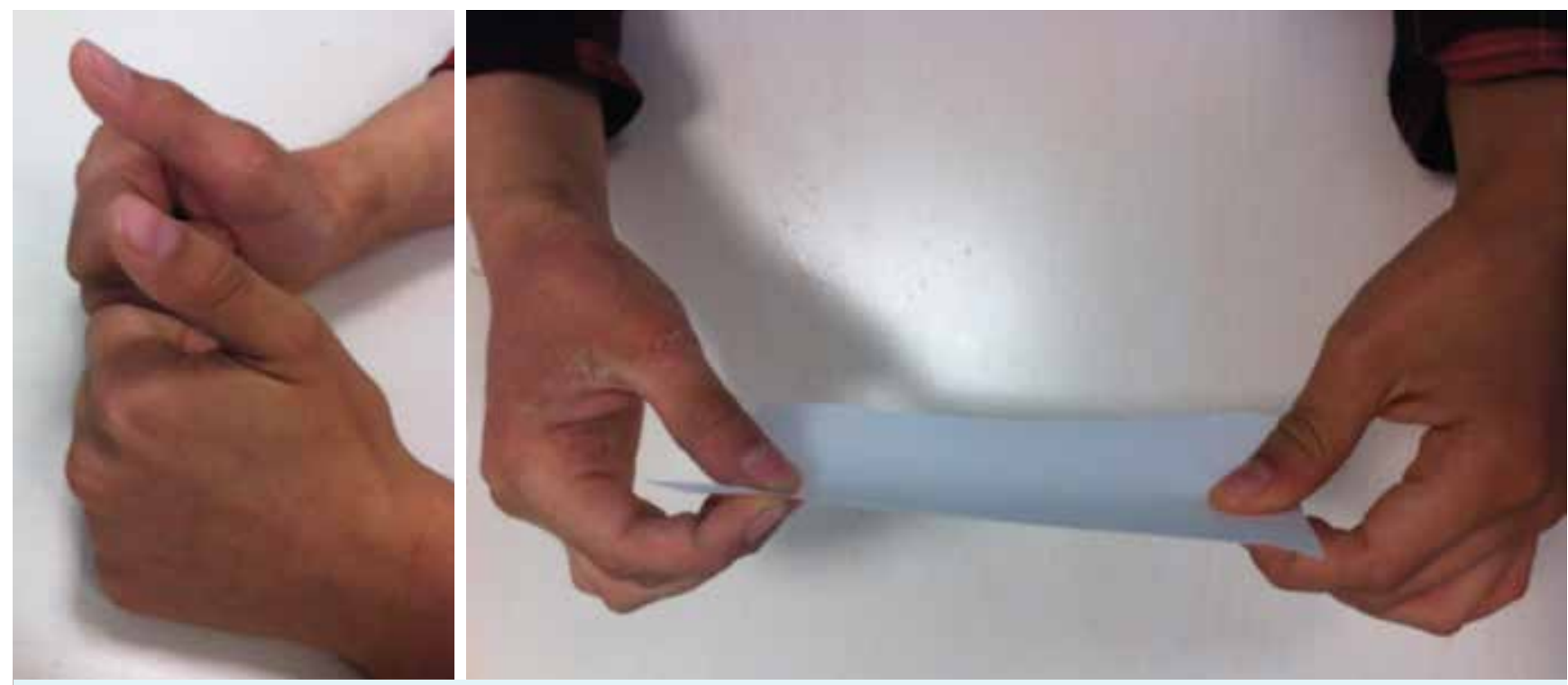

FIGURA 2. Boa recuperação funcional do polegar após remoção da imobilização.

redução fechada após anestesia local e realizada radiografia de controlo que demonstrou a completa redução da fratura. Foi então preconizada a imobilização por 3 semanas para descanso de partes moles e reavaliação em consulta externa com 6 semanas, com excelente recuperação funcional ao término destas.

\section{DISCUSSÃO}

Luxações isoladas das articulações metacarpofalângicas nas crianças são muito raras. ${ }^{1}$ No entanto, pela laxidez ligamentar e da maleabilidade da cartilagem, também podem ocorrer, sendo o polegar o dedo mais vulnerável para esta lesão. Farabeuf ${ }^{2}$ em 1876 classifica estas luxações em três tipos: incompleta, completa simples e completa complexa. Lesões incompletas são aquelas onde o ligamento colateral está intacto; nas completas simples, há lesão do ligamento colateral e/ou da placa volar mas não existe interposição que impeça a redução. Já nas completas e complexas existe interposição volar ou ligamentar que impede a redução fechada, com a indicação cirúrgica. ${ }^{2-5}$ Stener ${ }^{6}$ demonstrou em estudo cadavérico a lesão do ligamento colateral alertando para a necessidade da reparação deste. Em traumatismo de maior energia a luxação metacarpofalângica pode estar associada a luxação carpo-metacárpica constituindo um "metacarpo flutuante".?

O tratamento é quase sempre conservador após redução fechada. Porém, se a luxação for complexa, poderá ser necessária uma redução aberta, quando existe a interposição da placa volar e a extremidade do metacarpo envolvida pelo músculo flexor curto do polegar. ${ }^{5}$ Esta 
também pode ser presa por uma laçada formada pelo músculo flexor curto do polegar e o adutor do polegar, com o flexor longo do polegar deslocado na direção cubital, como nas luxações completas e complexas. ${ }^{5}$

\section{CONCLUSÃO}

Esta luxação, quando corretamente diagnosticada e reduzida, apresenta prognóstico favorável. ${ }^{1}$ Lesões ligamentares e instabilidade podem estar associadas, o que justifica a imobilização. A radiografia deve sempre ser realizada antes de qualquer manobra de redução de forma a diagnosticar e documentar as lesões fisárias associadas, uma vez que a luxação isolada é a exceção.

CONFLITOS DE INTERESSE: Os autores declaram não ter qualquer conflito de interesse na realização do presente trabalho.

PROTEÇÃO DE PESSOAS E ANIMAIS: Os autores declaram que os procedimentos seguidos na elaboração do presente trabalho estão em conformidade com as normas das comissões de investigação clínica e de ética, bem como da declaração de Helsínquia e da Associação Médica Mundial.

FONTES DE FINANCIAMENTO: Não houve qualquer fonte de financiamento na realização do presente trabalho.
CONFIDENCIALIDADE DOS DADOS: Os autores declaram ter seguido os protocolos da sua instituição acerca da publicação de dados de doentes.

\section{REFERÊNCIAS}

1. Maheshwari R, Sharma H, Duncan RD. Metacarpophalangeal joint dislocation of the thumb in children. J Bone Joint Surg Br. 2007;89:227-9.

2. Bohart PG, Gelberman RH, Vandell RF, Salamon PB. Complex dislocations of the metacarpophalangeal joint. Clin Orthop. 1982;164:208-10.

3. Kaplan EB. Dorsal dislocation of the metacarpophalangeal joint of the index finger. J Bone Joint Surg [Am]. 1957;39A:1081-6

4. Sodha S, Breslow D, Chang B. Percutaneous technique for reduction of complex metacarpophalangeal dislocations. Ann Plast Surg. 2004;52:562-6.

5. McLaughlin HL. Complex 'locked' dislocation of the metacarpophalangeal joint. J Trauma. 1965;5:683-8.

6. Stener B. Hyperextension injuries to the metacarpophalangeal joint of the thumb: rupture of ligaments, fracture of sesamoid bone, rupture of flexor pollicis brevis. Acta Chir Scand. 1963;125:275-93.

7. Drosos GI, Kayias EH, Tsioros K. "Floating thumb metacarpal" or complete dislocation of the thumb metacarpal: a case report and review of the literature. Injury. 2004;35:545-8. 